\title{
MULHERES NA CONTABILIDADE: OS ESTEREÓTIPOS SOCIALMENTE CONSTRUIDOS SOBRE A CONTADORA
}

\author{
Derley Junior Miranda Silva'
}

Marli Auxiliadora da Silva ${ }^{2}$

\begin{abstract}
Resumo: Investigou-se, neste estudo descritivo, a percepção dos profissionais de contabilidade com relação aos estereótipos associados à mulher contadora. É uma pesquisa com abordagem quantitativa, realizada por meio de levantamento junto a profissionais de ambos os gêneros da cidade de Uberlândia, em Minas Gerais, com registro ativo no Conselho Regional de Contabilidade de Minas Gerais (CRCMG), totalizando uma amostra por acessibilidade e não probabilística de 308 (trezentos e oito) respondentes. Mediante questionário foram coletadas informações sociodemográficas bem como os estereótipos atribuídos à mulher contadora pelos próprios profissionais de contabilidade, a partir de pares de adjetivos opostos em uma Escala de Diferencial Semântico. Usando-se o Teste de Hipóteses para Diferença de Proporções para tratamento estatístico dos dados rejeitou-se a hipótese H0: Não há diferença na proporção da estereotipagem da profissional contadora para os contadores e contadoras. Homens e mulheres percebem de forma distinta a mulher contadora quanto aos estereótipos: líder, prática, independente, confiante, com sentido de humor, conhecedora da realidade empresarial e sensível. Embora resultados de estudos anteriores apontem estereótipos negativos sobre a imagem da mulher contadora adjetivando-a como mal-humorada, imaginativa, submissa, melhor preparada para atividades repetitivas e operacionais e antissocial, estes estereótipos não foram apontados pelos partícipes desta pesquisa. No entanto, constatou-se, principalmente na percepção das próprias contadoras, dificuldades que as impedem de se destacarem no ambiente corporativo, ocupando as mesmas posições e recebendo os mesmos salários que profissionais do gênero masculino.
\end{abstract}

Palavras-chave: Gênero. Mulher contadora. Estereótipos. Escala de Diferencial Semântico. Desigualdades entre gêneros.

'derley_jr@hotmail.com - Universidade Federal de Uberlândia

${ }^{2}$ marli.silva@ufu.br - Universidade Federal de Uberlândia

- DOI: http://dx.doi.org/10.14392/asaa.2018110104

- Artigo submetido em: 14/02/2018. Aeito em: 29/05/2018 


\section{WOMEN IN ACCOUNTING: SOCIALLY CONSTRUCTED STEREOTYPES ABOUT THE FEMALE ACCOUNTANT}

Abstract: In this descriptive study, it was investigated the perception of accounting professionals regarding the stereotypes associated with the female accountant. It is a research with a quantitative approach, performed by means of a survey with professionals of both genders of the city of Uberlândia, Minas Gerais, with an active registration in the Regional Council of Accounting of Minas Gerais (CRCMG), summing up a sample for accessibility and non-probabilistic of 308 (three hundred and eight) respondents. Through questionnaires, sociodemographic data were collected as well as the stereotypes attributed to the woman accountant by the accounting professionals themselves, from pairs of opposing adjectives in a Semantic Differential Scale. Using the Hypothesis Test for Difference of Proportions for statistical treatment of the data the hypothesis $\mathrm{HO}$ was rejected: there is no difference in the proportion of the stereotyping of the female accountant to the male accountants and female accountants. Men and women perceive differently the female accountant as stereotypes: leader, practical, independent, confident, with sense of humor, knowledgeable about business reality and sensitive. Although results from previous studies point to negative stereotypes about the female accountant, labeling her as grumpy, imaginative, submissive, better prepared for repetitive and operational activities, and antisocial, these stereotypes were not pointed out by the participants in this research. However, it was found, mainly in the perception of the female accountants themselves, that they are unable to stand out in the corporate environment, filling up the same positions and receiving the same wages as male professionals.

Keywords: Gender. Female accountant. Stereotypes. Semantic Differential Scale. Inequalities between genders. 


\section{INTRODUÇÃO}

A s questões envolvendo diferenças de gêneros têm ganhado proporções significativas, especialmente no sentido de dar maior visibilidade à mulher como agente social e histórico, dissociando-a de seu papel de coadjuvante. Em relação ao gênero feminino, concepções culturais e sociais, definiram a imagem e as funções da mulher, tanto em relação a vida pessoal quanto à profissão. No ambiente familiar, desde o início da civilização a mulher era submissa ao homem, a quem era obrigada a servir permanentemente (Rochadel, 2007). Na educação, eram treinadas para funções de esposa e mãe, visando ao casamento e, naturalmente, à procriação da espécie (Mota \& Souza, 2012). No âmbito profissional, leis e culturas impediam-Ihes o exercício de uma profissão remunerada (Estevens \& Neto, 2015), ou qualificavam-nas para funções operacionais (Lemos Júnior, Santini \& Silveira, 2015).

Como resultado dessas concepções foram sendo atribuídos rótulos à mulher, frequentemente referidos como estereótipos (Wells, 2017). Como os estereótipos não se tratam de um conceito unívoco, sua generalização desprovida de conhecimento factual ou científico, pode levar a concepções falsas (Castro, Díaz, \& Vega, 1999; Lipmann, 1999; Martins, \& Rodrigues, 2004). Em se tratando do gênero feminino, a valorização dos estereótipos projeta sobre a mulher uma representação social que contribui não só para a imagem que se tem sobre elas, como também para as condições e circunstâncias que envolvem sua inserção social e profissional.

Em relação à contadora não há, na literatura internacional e nacional, consenso quanto aos estereótipos associados à imagem da profissional. Sem a pretensão de esgotar e apresentar a diversidade de pesquisas sobre o tema, destaca-se que alguns estudos seminais e outros mais atuais apresentam-nas como mal-humoradas e orgulhosas (Cory, 1992); suscetíveis ao estresse (Collins, 1993); frágeis emocionalmente e com dificuldades de relacionamento (Child, 1992; Hooks \& Cheramy, 1994); e melhor preparadas para atividades operacionais (Lemos Júnior, Santini \& Silveira, 2015).

Em outros estudos, todavia, não foram identificadas diferenças de gêneros, sendo os contadores vistos nas mesmas condições e estereotipados de modo similar à suas colegas de trabalho (Leong \& Hayes, 1990; White \&White, 2006; Leal, Miranda, Araújo e Borges (2014). É importante destacar, inclusive, resultado apresentado em estudo de Flynn, Earlie e Cross (2015), que evidencia que contadores de ambos os sexos acreditam que as mulheres são bem-sucedidas na profissão contábil quando se adaptam aos valores e normas ocupacionais masculinos. Desta forma, e comparando-se os resultados das pesquisas, nota-se que a contabilidade reflete as desigualdades não apenas estruturais, mas também profissionais, de gênero ainda existentes na contemporaneidade.

Ressalta-se, oportunamente, que os participantes dos estudos brasileiros onde os estereótipos são apontados, em sua maioria, são discentes ou o público em geral (Azevedo, 2010; Lopes, 2014; Miranda, Leal, Medeiros \& Lemes, 2015; Oliveira \& Leal, 2015). Tendo em vista que não foram confirmados, nas bases de dados investigadas, estudos nacionais relatando a opinião dos próprios profissionais de contabilidade sobre a imagem da mulher contadora, entende-se persistir uma lacuna nas discussões sobre a temática.

Nesse sentido, busca-se proporcionar contribuições adicionais às discussões a fim de responder à questão: Quais estereótipos são associados à mulher contadora pelos profissionais de contabilidade, de ambos os gêneros? Deste modo, ancorando-se nas Teorias de Gênero e Teoria das Representações Sociais, investigou-se a percepção de contadores e contadoras quanto aos estereótipos associados à mulher contadora, mediante a adaptação e uso dos instrumentos de pesquisa de Saemann e Crooker 
(1999) e Gomes (2009), que utilizam adjetivos opostos em uma Escala de Diferencial Semântico para a atribuição de estereótipos.

Este estudo que tem como pressuposto que os estereótipos socialmente construídos sobre a mulher contadora, por ambos os gêneros, diferem entre si, justifica-se pela necessidade de identificação da estereotipagem da mulher, no contexto contábil, pois, além de se configurar um tema contemporâneo, pode revelar novas percepções a respeito das representações sociais construídas historicamente em relação ao gênero feminino. Justifica-se, também, por revelar as convicções de contadores e contadoras em relação à mulher contadora.

\section{REVISÃO DE LITERATURA}

Optou-se por estruturar esta revisão de literatura em uma única seção, onde apresenta-se, inicialmente o conceito de gênero e suas abordagens teóricas, bem como apontamentos sobre a Teoria das Representações Sociais e estereótipos sob o enfoque de gênero. Em seguida faz-se uma discussão sobre o ingresso da mulher no mercado de trabalho e apresentam-se os estereótipos associados à sua imagem profissional, finalizando a revisão com estudos correlatos.

O conceito de gênero remete à ideia de que a diferença não está definida puramente no momento do nascimento, mas que é construída por meio de práticas sociais'masculinizantes'e 'feminizantes', congruentes às várias concepções estabelecidas em cada sociedade, sendo, também, uma forma primária de introduzir as relações de poder entre os indivíduos (Scott, 1988; Louro, 1995).

A discussão sobre gênero, em estudos feministas, fundamenta-se em teorias diversas. Sem a pretensão de mapear tais estudos ou teorias, apresenta-se discussão de Calás \& Smircich (2006), onde o gênero pode ser compreendido como uma construção social decorrente do sistema de dominação masculina (Teoria Feminista Radical); ou como classes ou categorias caracterizadas por relações de dominação e opressão que reforçam as desigualdades (Teoria Marxista); ou como processos sociais decorrentes de interseções de sexo, raça, ideologias e experiências de opressão patriarcal e do capitalismo (Teoria Socialista). Na Teoria Pós-Estruturalista, Calás \& Smircich (2006) apontam o gênero como uma categoria ambígua e flexível, fundeada em contextos socioculturais mutáveis e instáveis, que alteram seu significado conforme o contexto histórico, político e sociocultural.

A diversidade de abordagens sobre gênero denota, tradicionalmente, uma suposta inferioridade fisiológica, moral e intelectual a que as mulheres foram submetidas persiste e projeta uma representação social de inferioridade física e intelectual em relação aos homens, além de subordinação e opressão.

Como os estereótipos são comumente aceitos, grande número de pessoas passa a perceber um grupo ou indivíduo estereotipado com base em falsas premissas, socializando assim representações que passam a ser compartilhadas por grupos sociais. As representações, originam-se, num primeiro momento, nas comunicações, valores e ideias compartilhadas pelos grupos sociais, até se transformarem em práticas desejáveis ou aceitas pelo coletivo (Alves-Mazzotti, 2008; Moscovici, 1978; Sá, 1994; Souza Santos, \& Almeida, 2005).

Moscovici (1978) destaca que as representações sociais dos gêneros configuram uma forma de exercer e manter um estado de desequilíbrio, favorecendo, em nosso entendimento, a perpetuidade de percepções quanto à já citada inferioridade física e intelectual das mulheres em relação aos homens, além de subordinação e opressão. Essa estereotipagem persiste ao longo do tempo e marca a trajetória profissional das mulheres, independentemente da profissão. 
O ingresso da mulher no mercado de trabalho é atribuído ao processo de industrialização, decorrente da Revolução Industrial, e à possibilidade de independência oferecida pelo capitalismo às mulheres jovens e solteiras. Em ambas as situações o resultado foi a migração dos trabalhos artesanais e domésticos para lavanderias de fábricas urbanas e indústrias têxteis (Shorter, 1976; Abramo, 2007).

Mudanças na estrutura familiar patriarcal da sociedade - em que os homens eram colocados em uma posição de poder e sustentadores da família, enquanto as mulheres permaneciam em casa para realização dos trabalhos domésticos e criação dos filhos (Whiting \& Wright, 2001) - devido ao advento das grandes guerras mundiais também contribuíram para a ocupação feminina de postos de trabalho em indústrias (Araújo, 2004; Boniatti, Velho, Pereira, Pereira \& Oliveira, 2014) e para seu posicionamento frente aos negócios da família (Simões \& Hashimoto, 2012).

Na profissão contábil, o ingresso feminino foi marcado pela luta prática e ideológica que as mulheres do início do Século XX enfrentavam se quisessem se tornar atendentes ou assistentes contábeis (Cooper \&Taylor, 2000; Kirkham \& Loft, 1993; Lehman, 1992). As atividades operacionais, repetitivas e que exigiam paciência era compatível com as habilidades das mulheres (Holcombe, 1973) enquanto a ocupação de contador, socialmente superior e tradicionalmente masculina, resultou não apenas em uma hierarquia ocupacional da contabilidade, mas também em uma hierarquia de gênero (Kirkham \& Loft, 1993).

A distinção laboral do trabalho contábil, entre os gêneros, destacada em estudos da década de 1990, ainda persiste no Século XXI, como evidenciam dados estatísticos do Departamento Intersindical de Estatísticas e Estudos Socioeconômicos (DIEESE) e da Relação Anual de Informações Sociais (RAIS), que apontam diferenças ocupacionais e salariais (DIEESE, 2014, 2017; RAIS, 2017). No entanto, é interessante observar que embora a mulher ainda ocupe, predominantemente, funções operacionais e administrativas como refletem os registros relativos às ocupações no mercado de trabalho (RAIS, 2017), não há consenso sobre os estereótipos sobre sua imagem.

O dissenso, em nosso entendimento ocorre, porque estereótipos são como as crenças e percepções das características de um grupo, contendo como afirma Myers (2000) não apenas os traços desse grupo, mas também a abrangência com que são compartilhados, os quais podem ser precisos ou extremamente genéricos. A percepção que se tem do outro é subjetiva e, muitas vezes, distante da realidade objetiva, $\mathrm{e}$ por isso, Robbins (2005) e Schlee, Curren, Harich, \& Kiesler (2010) alertam que estereótipos incorretos e inapropriadamente atribuídos podem resultar em avaliações e expectativas inconsistentes e equivocadas.

A estereotipagem da mulher contadora, muito presente nas discussões de estudos da década de 1990, evidenciava uma constante busca por se assemelharem aos profissionais do gênero masculino: no final do Século XX, Hull e Umansky (1997), Johnson, Reckers e Anderson (1993), Smith e Briggs (1999) e Trapp, Hermanson e Turner (1989) chamam a atenção para a forma negativa como os estereótipos influenciavam a avaliação de contadoras, sobretudo em situações de recrutamento dos profissionais e da ascensão à posições por meio da mobilidade na hierarquia vertical, destacando a existência de um "teto de vidro" (glass ceiling) percebido em relação às oportunidades para contadoras avancem na profissão.

Silva, Dal Magro e Silva (2016) defendem a existência do glass ceiling na profissão contábil como causa para os cargos e salários mais baixos das contadoras, mesmo que elas ocupem funções semelhantes às de seus pares. Também Flynn, Earlie e Cross (2015), observaram que contadoras são minoria em cargos superiores e levam mais tempo que os seus colegas para receberem promoções, embora alguns partícipes desse estudo entendam que o glass ceiling tenha se enfraquecido e que não exista discriminação entre gêneros no contexto da profissão contábil. Para Flynn, Earlie e Cross (2015) há uma certa ironia estabelecida nas empresas contábeis, dada a divergência clara entre a percepção e a realidade vivida 
pelas mulheres contadoras, pois ambos os sexos acreditam que as mulheres são bem-sucedidas nessa profissão ao se adaptarem aos valores e normas ocupacionais masculinos.

Escolhas relacionadas ao estilo de vida estão entre os fatores utilizados para justificar a sub-representação das mulheres nos níveis de gerenciamento superiores. Keiran (2017) identificou que além da estrutura organizacional e da discriminação de gênero, as mulheres, em suas aspirações individuais e escolhas profissionais, tendem a buscar um equilíbrio entre a vida familiar e a profissional. Flynn, Earlie e Cross (2015) também observaram restrições no desenvolvimento da carreira das contadoras e indicaram que as mulheres tendem a atrasar o início de uma família ou diminuem suas aspirações profissionais depois de terem filhos.

Esse contexto não se resume aos dias atuais, como destacado por Hooks e Cheramy (1994), os quais chamaram a atenção para uma visão distorcida que empregadores tinham em relação às mulheres contadoras, especialmente em situações de maternidade, apontando o abandono de postos de trabalho após o nascimento dos filhos por razões puramente pessoais ou, conforme identificado por Whiting e Wrigth (2001), optando por empregos de meia jornada após o puerpério. Sobre uma possível orientação masculina estereotipada para acesso a níveis organizacionais mais elevados, Kanter (1977) e Lehman (1992) hipotetizam que geralmente as mulheres buscam se assemelhar aos homens que também ocupam essas posições.

A discussão ora apresentada aponta a necessidade de se considerar as questões de gênero na área contábil, especialmente porque destacam a necessidade de a mulher conciliar vida familiar e profissional, mas não remetem a discussão ao homem contador. Entende-se que este pode ser um indício que resulta na significativa associação de estereótipos positivos ao contador, inibindo a associação destas mesmas qualidades ao feminino (Young, 2013; Azevedo, 2014).

Nota-se que as representações sociais sobre o profissional de contabilidade, de ambos os gêneros ou do gênero feminino, e até mesmo da profissão contábil, construídas ao longo dos anos e aceitas pelo coletivo, são duais como refletem as conclusões de estudos anteriores que ora apontam uma imagem positiva, ora uma imagem estereotipada de forma negativa. Azevedo (2010) discutiu esse paradoxo destacando autores que, a partir de estudos empíricos ou de suas reflexões, elencam os estereótipos formados em relação ao profissional de contabilidade. Dando continuidade ao apanhado de Azevedo (2010) realizamos, sem a pretensão de esgotá-los, um resgate dos estereótipos evidenciados na literatura nacional, no período de 2010 a 2017 (Tabela 1).

Tabela 1: Alguns estereótipos atribuídos à profissão contábil e ao contador/contadora

\begin{tabular}{|c|c|c|}
\hline Autor(es/as) & Variável investigada e estereótipos encontrados & Público investigado \\
\hline Tonetto (2012) & $\begin{array}{l}\text { Profissional (mulher contadora): organizadas, detalhistas, responsáveis, } \\
\text { disciplinadas, ágeis e sensiveis. }\end{array}$ & $\begin{array}{l}\text { Egressas do curso de Ciências } \\
\text { Contabeis de uma universidade } \\
\text { brasileira }\end{array}$ \\
\hline $\begin{array}{l}\text { Leal, Miranda, Araújo, \& Borges } \\
\text { (2014) }\end{array}$ & $\begin{array}{l}\text { Profissional (ambos os gêneros): criatividade, dedicação aos estudos, trabalho } \\
\text { em equipe, comunicação, liderança, propensão ao risco e ética. }\end{array}$ & $\begin{array}{l}\text { Estudantes de Ciências Contábeis e } \\
\text { pelo público externo }\end{array}$ \\
\hline $\begin{array}{l}\text { Lemos Junior, Santini, \& Silveira, } \\
\qquad 2015\end{array}$ & $\begin{array}{l}\text { Profissional: (mulher contadora): melhor preparação para as atividades } \\
\text { operacionais da área, por serem mais detalhistas e dóceis do que o homem. }\end{array}$ & $\begin{array}{l}\text { Mulheres de um escritório de } \\
\text { contabilidade em Belo Horizonte }\end{array}$ \\
\hline Miranda \& Faria (2016) & $\begin{array}{c}\text { Profissão e profissional (ambos os gêneros): fraude, negócios suspeitos, } \\
\text { corrupçãa, desvios, demonstrações maquiadas e manobras. Profissional } \\
\text { contábil limitado aos relatórios e demonstrações que nem sempre se aplicam } \\
\text { à realidade. }\end{array}$ & $\begin{array}{l}\text { Notícias veiculadas em um jornal de } \\
\text { grande circulação no Brasil }\end{array}$ \\
\hline $\begin{array}{l}\text { Moura, Pereira, Miranda, \& } \\
\quad \text { Medeiros (2016) }\end{array}$ & $\begin{array}{l}\text { Profissional (ambos os gêneros): submisso, vilão, desagradável, chato, } \\
\text { antissocial, obsessivo, frio (negativos); criativo, competente, confiável, } \\
\text { dedicado, herói e um profissional que agrada o cliente com facilidade } \\
\text { (positivos). }\end{array}$ & $\begin{array}{l}\text { Obras literárias e cinematográficas } \\
\text { de diferentes épocas }\end{array}$ \\
\hline Silva, Silva, \& Santos (2017) & $\begin{array}{l}\text { Profissional (mulher contadora): sensibilidade, educação, organizaçãa, } \\
\text { honestidade, comprometimento, compreensibilidade, dedicação, paciência, } \\
\text { criatividade, eficiência, competência, interesse, disciplina, clareza, inteligência, } \\
\text { flexibilidade, versatilidade, percepção aguçada, dinamismo e neutralidade. }\end{array}$ & $\begin{array}{l}\text { Discentes do curso de Ciências } \\
\text { Contábeis }\end{array}$ \\
\hline
\end{tabular}

Fonte: Elaboração própria. 
A estereotipagem da mulher contadora é divergente em diversos estudos: enquanto Tonetto (2012) e Silva, Silva e Santos (2017) encontraram estereótipos positivos para a contadora, em Lemos Junior, Santini e Silveira (2015), a contadora possui uma imagem caracterizada por adjetivos não tão positivos. Quando o profissional, sem distinção de gênero, foi estereotipado por grupos sociais diferentes vê-se, novamente, a dualidade (Leal, Miranda, Araújo, \& Borges, 2014; Miranda \& Faria, 2016; Moura, Pereira, Miranda, \& Medeiros, 2016; Pinto, 2016). Destaca-se que Leal et al (2014), identificaram estereótipos similares para variáveis como criatividade, liderança, propensão ao risco e ética, para ambos os gêneros.

Em estudos internacionais a estereotipagem é, também, dual: Alev et al (2010) constataram que as contadoras, quando comparadas aos contadores, são estereotipadas positivamente como criativas e abertas à variedade, interessadas, excitantes, interativas, extrovertidas, conceituais, inovadoras, intuitivas, orientadas para as pessoas, efetivas, imaginativas, imprevisíveis, detalhistas, mutáveis, cuidadosas e matemáticas.

O dissenso quanto aos estereótipos em resultados de estudos, são observados também em fontes documentais, como apontado por Kyriacou (2015), que em análise de periódicos gregos, identificou que as mulheres são representadas e/ou apresentadas em papéis de apoio, como ouvintes, e muitas vezes invisíveis, enquanto os homens contadores sempre se apresentam em uma posição mais favorável, dando palestras, representados como donos de firmas contábeis e sendo assessorado por mulheres.

\section{ASPECTOS METODOLÓGICOS}

Para a realização deste estudo exploratório e descritivo, com abordagem quantitativa, realizou-se pesquisa de campo a fim de identificar, por meio da aplicação de questionários, as percepções de contadores e contadoras da cidade de Uberlândia em relação à imagem da mulher contadora. A população foi composta por profissionais de contabilidade, de ambos os gêneros, com registro ativo no Conselho Regional de Contabilidade de Minas Gerais (CRC-MG).

À época da coleta de dados, ocorrida de forma presencial durante os meses de agosto e setembro de 2017, o total de contadores e técnicos em contabilidade mineiros do gênero masculino somava 1.359 profissionais (58,4\%), enquanto as profissionais do gênero feminino totalizavam 972 mulheres (42,6\%) (CRC-MG, 2017). Como não foi obtido do CRC-MG o contato (e-mail) dos profissionais com registro ativo devido à política interna do Conselho e, também a quantidade de profissionais sindicalizados, em Uberlândia, não atendia a critérios de quantidade mínima necessária, adotou-se a amostragem não probabilística.

Ao decidir-se pela amostragem não probabilística e por acessibilidade, consultou-se o endereço de organizações contábeis em um site de busca online. De posse dos endereços e telefones foram contatados 352 (trezentos e cinquenta e dois) profissionais da cidade de Uberlândia-MG. Destes 44 (quarenta e quatro) não responderam ou responderam de forma incompleta ao questionário. Ao final a amostra foi composta por 308 (trezentos e oito) participantes com idade variável entre 21 e 75 anos, sendo 186 do gênero feminino e 122 do gênero masculino.

Para coleta dos dados utilizou-se um questionário composto por duas partes: na primeira solicitou-se aos participantes que fornecessem informações sociodemográficas. Em relação aos próprios participantes, as questões incluíram gênero, idade, nível de escolaridade mais elevado, registro profissional e forma de atuação. Os participantes também foram convidados a indicar uma possível situação de paternidade ou maternidade de filha/filhas para cruzamento dessa informação com as respostas atribuídas aos ad- 
jetivos de diferencial semântico categorizadores da imagem da mulher contadora a fim de identificar alteração na percepção dos respondentes quanto aos estereotipos percebidos por eles.

Na segunda parte, os participantes foram convidados a atribuir um adjetivo à mulher contadora, mediante o uso da Escala de Diferencial Semântico, adaptada de Saemann e Crooker (1999) e Gomes (2009). Em linhas gerais, a escala pensada na década de 1950 por Osgood, Suci e Tannenbaum, objetiva mensurar o significado conotativo dos conceitos ou expressões, os quais são destinados à investigação por meio do diferencial semântico e são identificados dentro de um espaço semântico (Nunnaly, 1970; Pereira, 1986; Passos, 2014). Ao final, em uma questão aberta os participantes opinaram sobre as ocupações e salários de ambos os profissionais, bem como possíveis estereótipos ainda atribuídos à mulher contadora.

A partir do instrumento usado por Saemann e Crooker (1999), com trinta e seis pares de adjetivos opostos, Gomes (2009) ampliou-os para 49 (quarenta e nove) os pares de adjetivos. $O$ instrumento de Gomes (2009) foi redigido originalmente em português de Portugal, sendo por isso feitas algumas adaptações (Tabela 2). Como este estudo se baseia na investigação da imagem da mulher contadora, todos os adjetivos biformes foram alterados para o gênero feminino.

Tabela 2: Adjetivos adaptados

\begin{tabular}{|c|c|}
\hline Adjetivos em português - Portugal & Adjetivos em português - Brasil \\
\hline Aborrecido/Interessante & Desinteressante/Interessante \\
\hline $\begin{array}{c}\text { Mal conselheiro de negócios } \\
\text { Bom conselheiro de negócios }\end{array}$ & $\begin{array}{c}\text { Má conselheira de negócios } \\
\text { Boa conselheira de negócios }\end{array}$ \\
\hline Monótono/Excitante & Monótona/Dinâmica \\
\hline Inflexível/Adaptável & Inflexível/Flexível \\
\hline Com sentido de humor/Sem sentido de humor & Bem humorada / Mal humorada \\
\hline Conservador/Liberal & Conservadora/Arrojada \\
\hline Fisicamente pouco atraente/Fisicamente atraente & Pouco atraente fisicamente/Fisicamente atraente \\
\hline Bons conhecimentos de fiscalidade & Bons conhecimentos de fiscalização \\
\hline Fracos conhecimentos de fiscalidade & Fracos conhecimentos de fiscalização \\
\hline Sofisticada/Totó & Sofisticada/Simples \\
\hline Sem ética / Ética & Antiética/Ética \\
\hline Vulgar/Carismático & Vulgar/Elegante \\
\hline Homem/Mulher & Séria/Carismática \\
\hline
\end{tabular}

Fonte: Dados da pesquisa (2017).

Para cada par de adjetivos, os participantes foram orientados a marcarem um X quanto à proximidade de sua resposta em relação a cada adjetivo. Na escala de proximidade, similar à escala Likert, os números 2 e 4 significam concordância parcial; 1 e 5 significam concordância total; o 3 significa a neutralidade em relação àquele adjetivo. Caso o participante assinalasse sua resposta conforme a situação apresentada (Tabela 3), sinalizaria que ele concorda totalmente que a contadora é uma profissional criativa. No ponto 3 da escala, classificado como'Neutro', as respostas indicam que a contadora não é estereotipada naquela característica.

Tabela 2: Adjetivos adaptados

\begin{tabular}{|c|c|c|c|c|c|c|}
\hline & 1 & 2 & 3 & 4 & 5 & \\
\hline Criativa & $\mathrm{X}$ & & & & & Rotineira \\
\hline
\end{tabular}

Fonte: Dados da pesquisa (2017). 
Considerando a ausência de estudos que investigaram a estereotipagem da contadora na perspectiva do próprio profissional, tem-se a hipótese estatística $\mathrm{H}_{0}$ : Não há diferença na proporção da estereotipagem da profissional contadora para os contadores e contadoras. Uma rejeição da hipótese nula $(\mathrm{H} 0)$ indica que os gêneros compreendem determinado adjetivo de maneira diferente. Adotou-se um nível de significância de 95\% e Z crítico de 1,96 para uma análise bicaudal das respostas.

O tratamento quantitativo dos dados foi realizado mediante o uso do software RStudio. Utilizou-se a análise das frequências absolutas obtidas, de forma a evidenciar em qual adjetivo as respostas mais se concentraram. Também foi usado o Teste de Hipóteses para Diferença de Proporções no sentido de confirmar a proporção em que os gêneros percebem os estereótipos (Morettin \& Bussab, 2010; Tavares, 2014). Assim, cada variável (par de adjetivos) analisada possui dois adjetivos (ou características) sendo, por isso, testadas as três opções possíveis de respostas: uma para cada adjetivo (característica) e outra para a condição 'Neutro'.

\section{DISCUSSÃO DOS RESULTADOS}

Na análise descritiva das variáveis sociodemográficas relacionou-se a variável gênero à forma de atuação, de forma a conhecer as características da amostra selecionada distribuídas conforme o gênero à que pertencem (Tabela 4). Também foram resgatados, para comparação, dados estatísticos relacionados a categorias como ocupação e salários divulgados pela RAIS.

Tabela 4: Características gerais segundo a forma de atuação, por gênero

\begin{tabular}{|c|c|c|c|c|c|c|c|c|c|c|c|c|c|}
\hline \multicolumn{14}{|c|}{ Forma de Atuação } \\
\hline & & \multicolumn{2}{|c|}{ Autônoma (a) } & \multicolumn{2}{|c|}{$\begin{array}{l}\text { Empregado/a de } \\
\text { instituição privada }\end{array}$} & \multicolumn{2}{|c|}{$\begin{array}{l}\text { Proprietário/a } \\
\text { de organização } \\
\text { contábil }\end{array}$} & \multicolumn{2}{|c|}{$\begin{array}{l}\text { Funcionário/a } \\
\text { público/a }\end{array}$} & \multicolumn{2}{|c|}{ Outro } & \multicolumn{2}{|c|}{ Total } \\
\hline \multirow{3}{*}{ Gênero } & & $f$ & $f(\%)$ & $f$ & $f(\%)$ & f1 & $f(\%)$ & $f$ & $f(\%)$ & $f$ & $f(\%)$ & $f$ & $f(\%)$ \\
\hline & Feminino & 23 & 56,1 & 116 & 64,1 & 18 & 38,3 & 17 & 85,0 & 12 & 63,2 & 186 & 60,4 \\
\hline & Masculino & 18 & 43,9 & 65 & 35,9 & 29 & 61,7 & 3 & 15,0 & 7 & 36,8 & 122 & 39,6 \\
\hline \multicolumn{2}{|c|}{ Total } & 41 & 100,0 & 181 & 100,0 & 47 & 100,0 & 20 & 100,0 & 19 & 100,0 & 308 & 100,0 \\
\hline
\end{tabular}

Fonte: Dados da pesquisa (2017).

Os respondentes, na maioria, são do gênero feminino ( $n=186 ; 60,4 \%)$. Quanto à forma de atuação, a maior parte $(n=181 ; 58,8 \%)$ atua como empregados de instituições privadas, ou seja, em organizações contábeis, sendo 64,1\% mulheres. Entre aqueles que são proprietários de organizações contábeis, os homens são maioria ( $n=47 ; 15,3 \%$ ). Mediante esses resultados, notam-se indícios de que as mulheres ainda trabalham como empregadas nas organizações, situação essa que é corroborada por dados estatísticos da RAIS.

A partir da idade informada pelos respondentes fez-se um agrupamento das diferentes faixas etárias utilizando-se os mesmos intervalos adotados pela Classificação Brasileira de Ocupações 2002 (CBO). A maior parte de contadores e contadoras participantes desta pesquisa possuíam idade variável entre 30 e 39 anos ( $n=110 ; 35,7 \%)$, seguidos por aqueles com 25 a 29 anos ( $n=80 ; 26,0 \%)$, e 40 a 49 anos ( $n=50 ; 16,2 \%)$. Novamente há uma aderência aos dados da RAIS, para Minas Gerais, onde 32,1\% dos trabalhadores com registro em carteira de trabalho, estão na faixa etária de 30 a 39 anos, e 21,8\% entre 25 e 29 anos (RAIS, 2017).

Embora a questão que investigou a ocupação dos respondentes, não tenha sido alinhada às ocupações descritas pela CBO 2002, os dados denotam que a maioria ( $n=195 ; 63,3 \%$ ) ocupa funções que 
exigem formação superior (contador geral e público, auditor, perito contábil), indicando que são bacharéis em contabilidade (contadores/contadoras). Possivelmente aqueles respondentes que assinalaram a opção 'Outro' ( $n=113 ; 36,7 \%$ ), quanto à ocupação, exerçam funções de auxiliar de contabilidade ou assistente contábil. Entre os participantes desta pesquisa, são as mulheres ( $n=73$ ) que ocupam, em maior frequência, as 'outras'áreas de atuação, assim como também são as mulheres que exercem essa mesma função como apontam dados estatísticos da RAIS (2017).

\subsection{Discussão sobre a estereotipagem da profissional contadora}

Inicialmente analisou-se os dois conjuntos de percepções (masculinas e femininas) no Teste de Diferença entre as Proporções que avaliou a estereotipagem para a hipótese H0. Testou-se o gênero com cada um dos 49 (quarenta e nove) adjetivos, apresentando-se, dessa forma, uma mesma variável três vezes: uma para o adjetivo 1 (característica 1) - à esquerda - outra para o adjetivo 2 (característica 2) - à direita - e outra para a característica Neutro. As proporções das respostas para cada adjetivo, destacando a significância estatística, assim como o valor de Z e a significância do teste são vistas na Tabela 5.

Tabela 5: Características com significância estatística no Teste de Hipóteses para a Diferença entre as Proporções da Mulher Contadora

\begin{tabular}{|c|c|c|c|c|c|c|c|}
\hline Variável & Característica & p1 (fem.) & p2 (masc.) & n1 & n2 & zcalc & p-valor \\
\hline Lid_Subord & Líder & $59,68 \%$ & $44,26 \%$ & 186 & 122 & 2,6531 & 0,0080 \\
\hline Lid_Subord & Neutro & $27,42 \%$ & $44,26 \%$ & 186 & 122 & $-3,0499$ & 0,0023 \\
\hline Prat_Teor & Prática & $54,84 \%$ & $41,80 \%$ & 186 & 122 & 2,2378 & 0,0252 \\
\hline Monot_Dinam & Neutro & $26,88 \%$ & $38,52 \%$ & 186 & 122 & $-2,1515$ & 0,0314 \\
\hline Indep_Depend & Independente & $66,67 \%$ & $53,28 \%$ & 186 & 122 & 2,3601 & 0,0183 \\
\hline Conf_Inseg & Confiante & $76,34 \%$ & $64,75 \%$ & 186 & 122 & 2,2097 & 0,0271 \\
\hline Csenthum_Ssenthum & ComSentimentoHumor & $52,15 \%$ & $64,75 \%$ & 186 & 122 & $-2,1861$ & 0,0288 \\
\hline Realempr_Preocnum & ConhRealidaEmpresarial & $65,59 \%$ & $50,82 \%$ & 186 & 122 & 2,5854 & 0,0097 \\
\hline Realempr_Preocnum & Neutro & $28,49 \%$ & $41,80 \%$ & 186 & 122 & $-2,4155$ & 0,0157 \\
\hline Sens_Insens & Sensível & $46,77 \%$ & $59,02 \%$ & 186 & 122 & $-2,1027$ & 0,0355 \\
\hline Exper_Inexper & Neutro & $27,96 \%$ & $39,34 \%$ & 186 & 122 & $-2,0874$ & 0,0369 \\
\hline
\end{tabular}

Fonte: Dados da pesquisa (2017).

Ambos os gêneros (Tabela 5) estereotiparam contadora como: líder, prática, dinâmica, independente, confiante, com sentimento de humor (bem-humorada), conhecedora da realidade empresarial e sensível. Homens e mulheres também concordam que a contadora é íntegra, otimista, inteligente, interessante, organizada, honesta, boa conselheira dos negócios, corajosa, sociável, extrovertida, formal, flexível, competente, gentil, educada, realista, responsável, bons conhecimentos de matemática, possuidora de bons conhecimentos de informática e de fiscalização, ética, bem vestida, eficiente, criativa, elegante, cativante.

Quanto à característica Neutro os resultados evidenciam a inexistência, para ambos os gêneros, de estereótipos relacionados à contadora para as variáveis: 'vestida de cores brilhantes/vestida de cores neutras', 'rica/pobre,' 'convencional/original', 'calma/nervosa', 'pouco atraente fisicamente/fisicamente atraente,',fora de moda/na moda,'tímida/desinibida,'sofisticada/simples,'séria/carismática,'experiente, rígida/versátil'. A proporção atribuída à característica Neutro foi maior que aquela atribuída a ambos os pares de adjetivos opostos.

Divergências nas estereotipagens foram identificadas para algumas variáveis, como 'fisicamente ativa/sedentária', em que as contadoras se consideram fisicamente 'ativas', enquanto os homens entendem que essa variável independe do gênero. As contadoras também se consideraram 'conservadoras' 
e 'ambiciosas', não sendo indicados estereótipos para essas variáveis na percepção dos homens. O gênero masculino percebe a mulher contadora como 'analítica', já as mulheres mantiveram-se neutras quanto a essa variável.

Apesar de a contadora ter sido estereotipada como 'líder', no que diz respeito à significância das proporções (Tabela 5) há uma relação significativa entre os gêneros para as características líder e neutro ( $p$-valor $=0,0080$ e $p$-valor $=0,0023$, respectivamente). Isso quer dizer que o gênero feminino se percebe como líder em uma proporção maior que o percebido pelo gênero masculino, o qual também indicou diferença estatística na percepção para o Neutro. Em outras palavras, as mulheres se reconhecem como líder, enquanto que para os homens essa característica parece independer do gênero.

Observam-se, também, percepções diferentes de homens e mulheres para a variável 'prática/teórica', na qual a contadora foi estereotipada como'prática'. A significância do teste ( $p$-valor $=0,0252)$ indica que a própria contadora se vê como'prática' em uma proporção maior que o gênero masculino (Tabela 5). Essa ocorrência é observada, também, para a variável'monótona/dinâmica'. No entanto, neste caso em que a contadora foi percebida por ambos os gêneros como 'dinâmica', houve diferença estatística naqueles que perceberam o'Neutro' como característica da variável'monótona/dinâmica' ( $p$-valor=0,0314).

Em outro caso de significância estatística, ambos os gêneros estereotipam a contadora como independente, confiante e conhecedora da realidade empresarial. Contudo as percepções são diferentes entre os gêneros: a percepção das mulheres, quanto a essas características, apresenta proporções maiores quando comparadas às respostas dos homens ( $p$-valor $=0,0183 ; 0,0271$ e 0,0097 , para 'independente,',confiante', e'conhecedora da realidade empresarial', respectivamente).

Curiosamente as proporções das respostas do gênero masculino foram maiores e estatisticamente diferentes das proporções do gênero feminino para as características 'com sentido de humor'e 'sensível' ( $p$-valor $=0,0288$ e 0,0355 , respectivamente). A mulher se estereotipa positivamente quanto a essas características, mas as proporções maiores (Tabela 5) são atribuídas pelo homem.

Por fim, constatou-se diferença estatística para as variáveis 'conhecedora da realidade empresarial/ só preocupada com números'e'experiente/inexperiente.' Ainda que ambos os gêneros concordem que a contadora conheça a realidade da empresa e sejam profissionais experientes, há diferença estatística para a característica Neutro em ambas as variáveis ( $p$-valor $=0,0157$ e $p$-valor $=0,0369$ ), sendo o respondente homem propenso à neutralidade em maior proporção.

Os resultados apresentados confirmam mudanças na estereotipagem da contadora. Em relação a aparência da contadora, à exceção do estereótipo sobre a vestimenta que estereotipa a contadora como bem vestida, chama-se atenção para a não existência de estereótipos ligados à aparência e a atributos físicos como 'beleza' entre outros. É um resultado curioso, visto que quando retratada em obras cinematográficas, por exemplo, a contadora se sobressai mais por sua beleza que por outras características (Cory, 1992); sexy, bela e poderosa (Moura et al, 2016).

Ainda, em se tratando da aparência física, contadoras pouco atraentes fisicamente tinham menos chances de avançar em suas carreiras na argumentação de Anderson, Johnson e Reckers (1994). Todavia, não há aderência dessas considerações com as evidências deste estudo que não encontrou estereótipos para a característica 'fisicamente atraente/não atraente fisicamente'. É uma constatação interessante, principalmente quando se reflete sobre a representação socialmente construída de que um fator como a beleza possa ser um critério de progressão na carreira como entendido por Anderson, Johnson e Reckers (1994).

Os resultados deste estudo diferem, também, de outros já relatados na literatura quanto aos adjetivos opostos 'calma/nervosa': de forma contrária ao discurso de Collins (1993), que descreveu as contadoras 
mais próximas do estresse do que seus colegas de trabalho, sendo mais suscetíveis a mudanças de humor, pois as evidências estatísticas (Tabela 5) confirmam a existência de estereótipos relacionadas ao ânimo da contadora, mas nesse caso, a profissional é estereotipada positivamente como 'bem-humorada.' Outra característica que merece destaque e, que difere da estereotipagem já observada, é que neste estudo, tanto os contadores quanto as contadoras, indicaram a característica de 'líder' à mulher contadora. Sobre a liderança, estudo de Miranda et al (2014) relatou que são os contadores quem mais se destacam mais por essa característica.

Entender que as mulheres não são capazes de serem assertivas em decisões empresariais, ou que não podem assumir papéis de liderança, ou até que elas não contribuem tanto para uma empresa quanto os homens (Alev et al, 2010) parecem concepções ultrapassadas e contrariadas com os estereótipos identificados nesta pesquisa onde a contadora foi reconhecida como líder e conhecedora da realidade empresarial. Essas características contribuem não só para a confirmação da igualdade, no âmbito profissional, entre os gêneros como também colocam as mulheres no mesmo patamar que os homens no ambiente empresarial.

Em relação aos estereótipos positivos confirmou-se a maioria deles. A exemplo do estudo de Alev et al (2010) onde a contadora foi descrita como 'extrovertida,' 'criativa,',efetivas', 'interativas', 'sociáveis' e 'matemáticas', também nesse estudo, os profissionais uberlandenses, independentemente do gênero estereotipam a mulher contadora com essas características. 'Organizadas', 'responsáveis' e 'sensíveis' também são outros exemplos de estereótipos encontrados que reafirmam aqueles já apresentados por Tonetto (2012).

Estereótipos que podem ser considerados como positivos à imagem da mulher contadora, aqui evidenciados, corroboram com estudos de Davidson e Dalby (1993) que já na década de 1990 estereotiparam as contadoras como 'inteligentes', 'confiantes' e 'mentes abertas'. Porém, por outro lado, contrariam outros estereótipos relatados pelos mesmos autores como 'teimosas' e 'difíceis de serem conduzidas', já que neste estudo a mulher contadora foi estereotipada como 'flexível'.

Child (1992) refletiu sobre aspectos emocionais das contadoras no ambiente empresarial e relata a fala de contadores que apontam as mulheres (contadoras) como muito emocionais; choram com mais facilidade; não se relacionam muito bem com outras colegas de trabalho e que perdem o interesse no trabalho em situação de maternidade. Na atual pesquisa os resultados até apontam que as contadoras são estereotipadas como pessoas sensíveis; no entanto, não se pode afirmar, com base nesses resultados, que essa característica afete o seu desempenho no trabalho. Inclusive, alguns estereótipos se opõem às considerações de Child (1992), pois a contadora foi reconhecida, pelos próprios respondentes do gênero masculino, como sociável, gentil e cativante, características essas que contrariam o histórico de dificuldades de relacionamento com outras colegas contadoras.

Leal et al (2014) relata que, embora não se possa afirmar estatisticamente, o homem contador é visto como mais criativo, líder e ético que as contadoras. Apesar de este estudo ter se limitado a conhecer a percepção sobre a mulher contadora, não buscando entender ou explicar, em profundidade, os estereótipos relacionados à imagem da contadora (ou contador), entende-se que essas características também estão associadas à imagem da mulher contadora, pois estes atributos foram atribuídos às contadoras. Já o estudo de Moura et al (2016) chama a atenção por trazer características que se reafirmaram (competência) e características que foram discordantes (antissocial, fria, desonesta e antiética), uma vez que nesta pesquisa a mulher contadora foi relatada, por ela própria e pelos respondentes do gênero masculino, como 'sensível', 'honesta' e 'ética'. 
Por fim, ainda que a pesquisa de Silva, Silva e Santos (2017) tenha sido realizada com uma amostra de discentes, seus resultados são semelhantes aos achados desta pesquisa. Em ambos os estudos a imagem da mulher contadora é de pessoa sensível, educada, organizada, honesta, criativa, eficiente, competente, interessada, inteligente, flexível e dinâmica. Porém, ao contrário de Silva, Silva e Santos (2017), onde a mulher foi considerada mais apta para atividades rotineiras, não se confirmou esse estereótipo, inclusive havendo proporção maior para aqueles que percebem a contadora como 'criativa' ao invés de 'rotineira'.

É evidente que nas últimas décadas, as mudanças provocadas pelo aumento de escolaridade, ascensão na carreira e níveis salariais (RAIS, 2017), parecem ter se estendido à percepção social da imagem da contadora de forma positiva. Observa-se na Figura 1 uma distribuição semelhante para o gênero feminino e masculino, o que pode ser um indicativo de que, talvez, os profissionais do gênero masculino, não percebam a mulher contadora de forma diferente, ao contrário de respondentes (de estudos anteriores) que ainda não atuam profissionalmente. Esse resultado ao ser cotejado com as considerações de Flynn, Earlie e Cross (2015), evidencia distinções, pois contadores irlandeses, de ambos os sexos, acreditam que para serem bem-sucedidas na profissão contábil as mulheres se adaptam aos valores e normas ocupacionais masculinos.

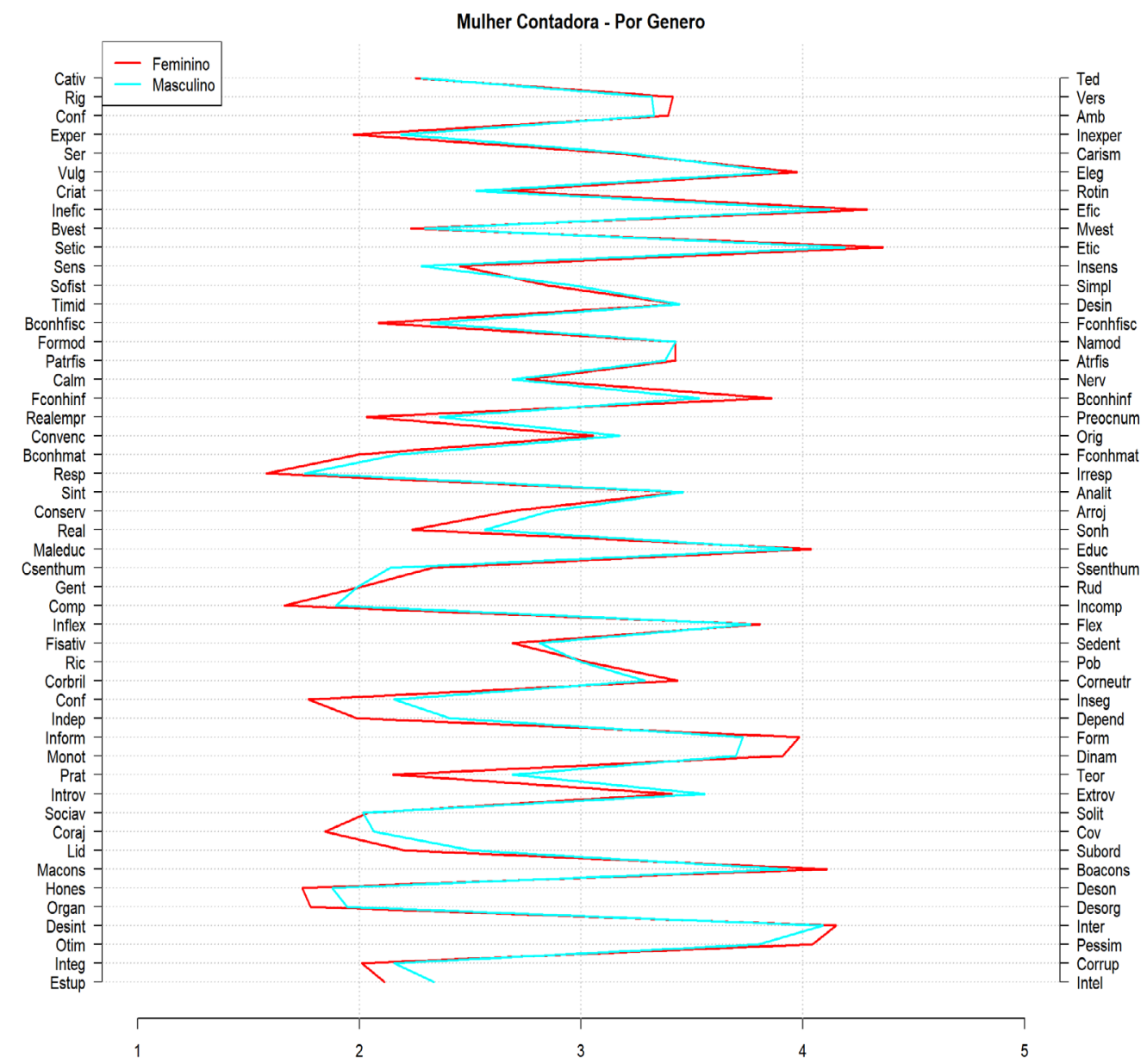

Fonte: Dados da pesquisa (2017).

Figura 1: Distribuiçẫo das frequências da estereotipagem da mulher contadora por gênero 
A partir dos resultados e discussões realizadas rejeita-se a hipótese H0 de não existência de diferença na proporção de estereotipagem da profissional contadora pelos próprios contadores e contadoras. Discussão adicional com o propósito de averiguar se a condição de paternidade e maternidade de filha/filhas, de alguma forma, influencia na percepção do profissional, quanto à imagem da contadora é apresentada a seguir.

As respostas à questão sobre paternidade e maternidade, inserida na primeira parte do questionário, foram tratadas por meio do teste de diferença de proporções a partir da percepção daqueles que possuem filha/filhas e daqueles que não as possuem a fim de verificar existência de diferenças significativas para as variáveis. Para a análise desta situação, a segregação das respostas não foi por gênero, mas sim por participantes que declararam possuir ou não filha/filhas. Apenas as variáveis com significância estatística foram elencadas na Tabela 6.

Tabela 6: Teste de Hipóteses para a Diferença entre as Proporções da perçepção sobre a mulher contadora em situação de paternidade/maternidade

\begin{tabular}{|c|c|c|c|c|c|c|c|}
\hline Variável & Característica & p1 (sim) & p2 (não) & $\mathrm{n} 1^{*}$ & $\mathrm{n}^{*}$ & zcalc & p-valor \\
\hline Integ_Corrup & Corrupta & $20,37 \%$ & $7,61 \%$ & 92 & 216 & 3,2229 & 0,0013 \\
\hline Estup_Intel & Estúpida & $12,50 \%$ & $5,43 \%$ & 92 & 216 & 2,1487 & 0,0317 \\
\hline $\begin{array}{l}\text { Macons_ } \\
\text { Boacons }\end{array}$ & BoaConselheNegócios & $69,91 \%$ & $57,61 \%$ & 92 & 216 & 2,0281 & 0,0426 \\
\hline Lid_Subord & Neutro & $27,42 \%$ & $44,26 \%$ & 92 & 216 & $-2,7708$ & 0,0056 \\
\hline Sociav_Solit & Solitária & $11,11 \%$ & $4,35 \%$ & 92 & 216 & 2,2248 & 0,0261 \\
\hline Monot_Dinam & Neutro & $26,88 \%$ & $38,52 \%$ & 92 & 216 & $-1,9601$ & 0,0500 \\
\hline Inform_Form & Formal & $64,35 \%$ & $47,83 \%$ & 92 & 216 & 2,6589 & 0,0078 \\
\hline Conf_Inseg & Confiante & $75,93 \%$ & $61,96 \%$ & 92 & 216 & 2,3709 & 0,0177 \\
\hline $\begin{array}{l}\text { Corbril__ } \\
\text { Corneutr }\end{array}$ & Cores Neutras & $40,28 \%$ & $28,26 \%$ & 92 & 216 & 2,0718 & 0,0383 \\
\hline Ric_Pob & Pobre & $19,44 \%$ & $10,87 \%$ & 92 & 216 & 2,0199 & 0,0434 \\
\hline Fisativ_Sedent & Sedentária & $24,54 \%$ & $13,04 \%$ & 92 & 216 & 2,4886 & 0,0128 \\
\hline Comp_Incomp & Competente & $81,48 \%$ & $67,39 \%$ & 92 & 216 & 2,5098 & 0,0121 \\
\hline $\begin{array}{l}\text { Realempr_- } \\
\text { Preocnum }\end{array}$ & Neutro & $28,49 \%$ & $41,80 \%$ & 92 & 216 & $-2,2043$ & 0,0275 \\
\hline Calm_Nerv & Nervosa & $24,07 \%$ & $14,13 \%$ & 92 & 216 & 2,1213 & 0,0339 \\
\hline Formod_Namod & Fora de moda & $10,19 \%$ & $3,26 \%$ & 92 & 216 & 2,4762 & 0,0133 \\
\hline $\begin{array}{l}\text { Bconhfisc_ } \\
\text { Fconhfisc }\end{array}$ & BonsConhFiscalização & $65,74 \%$ & $52,17 \%$ & 92 & 216 & 2,1966 & 0,0281 \\
\hline Sofist_Simpl & Sofisticada & $33,33 \%$ & $21,74 \%$ & 92 & 216 & 2,1450 & 0,0320 \\
\hline Bvest_Mvest & Mal vestida & $9,72 \%$ & $3,26 \%$ & 92 & 216 & 2,3395 & 0,0193 \\
\hline Ser_Carism & Carismática & $38,89 \%$ & $26,09 \%$ & 92 & 216 & 2,2459 & 0,0247 \\
\hline
\end{tabular}

A Confirmou-se a existência de diferenças estatísticas nas proporções para todas as variáveis expostas na Tabela 6. Esse resultado pode indicar que quando o profissional, independentemente do gênero, possui filha/filhas sua percepção em relação à contadora é diferente daqueles participantes que não as possuem. A estereotipagem difere estatisticamente e com predominância para a característica'Neutro' nas variáveis:'líder/subordinada' ( $p$-valor=0,0056),'monótona/dinâmica' ( $p$-valor=0,0500) e'conhecedora da realidade empresarial/só preocupada com números' ( $\mathrm{p}$-valor=0,0275).

As percepções dos respondentes que possuem filha/filhas foram maiores e estatisticamente diferentes das percepções daqueles que não as possuem para as características 'corrupta' (p-valor=0,0013), 'estúpida' ( $p$-valor=0,0317), 'boa conselheira dos negócios' ( $p$-valor=0,0426), 'sociável' ( $p$-valor=0,0261), formal ( $p$-valor=0,0078), confiante ( $p$-valor=0,0177), vestida de cores neutras ( $p$-valor=0,0383), pobre 
( $p$-valor=0,0434), sedentária ( $p$-valor=0,0128), competente ( $p$-valor=0,0121), nervosa ( $p$-valor=0,0339), fora de moda ( $p$-valor=0,0133), bons conselhos de fiscalização ( $p$-valor=0,0281), sofisticada ( $p$-valor=0,0320), mal vestida ( $p$-valor=0,0193) e carismática ( $p$-valor=0,0247).

Profissionais de contabilidade que possuem filha/filhas percebem a mulher contadora como 'conservadora','analítica' e'ambiciosa', enquanto que profissionais que não as possuem entendem que não existem estereótipos para as variáveis 'conservadora/arrojada', 'sintética/analítica' e 'conformada/ ambiciosa'.

O indicativo de que a paternidade/maternidade de filha/filhas leva a percepções diferenciadas parece denotar que um maior contato com um grupo ou indivíduo, ou seja, o contato do profissional com filha/filhas, pode resultar em melhor relação entre os envolvidos, diminuindo a percepção negativa que este, eventualmente, possa ter em relação à contadora.

\section{CONSIDERAÇÕES FINAIS}

Embora contrariando, parcialmente, a hipótese do estudo de que os estereótipos socialmente construídos sobre a mulher contadora, por ambos os gêneros, diferem entre si, os resultados desta pesquisa permitem conclusões interessantes. O estudo permitiu identificar a percepção dos próprios profissionais de contabilidade, com registro ativo no CRC-MG, e atuantes na cidade de Uberlândia, com relação aos estereótipos associados à mulher contadora. Tinha-se como pressuposto que as estereotipagens realizadas por cada profissional - homem ou mulher, contador e contadora - fossem diferentes quando estes avaliassem os pares de adjetivos da Escala de Diferencial Semântico.

A hipótese de que as percepções diferem não é conclusiva, pois na opinião dos contadores e contadoras, a estereotipagem para a maioria dos adjetivos se assemelha, e a construção social da imagem da mulher, pelos próprios profissionais, é semelhante para características como liderança, integridade, otimismo, inteligência, organização, honestidade e ética, entre outros. Quanto à hipótese de que não existe diferença na proporção da estereotipagem da mulher contadora rejeitou-se a hipótese nula: não é possível afirmar que não exista diferença na proporção da estereotipagem da mulher contadora pelos próprios profissionais.

Quanto à imagem da contadora, apesar de diferenças entre as percepções dos gêneros masculino e feminino, confirmou-se que esta é estereotipada por ambos os gêneros como íntegra, otimista, inteligente, interessante, organizada, honesta, boa conselheira de negócios, líder, corajosa, sociável, extrovertida, prática, dinâmica, formal, independente, confiante, flexível, competente, gentil, bem humorada, educada, realista, responsável, possuidora de bons conhecimentos de matemática, informática e fiscalização, conhecedora da realidade empresarial, sensível, ética, bem vestida, eficiente, criativa, elegante, cativante.

Conclui-se que os estereótipos atribuídos à mulher, neste estudo, projetam novas representações sociais da mulher contadora. Na presente pesquisa a mulher contadora, foi estereotipada por ela mesma e por seus colegas de profissão, como uma profissional bem-humorada, diferentemente de Cory (1992) que a retratou como mal-humorada;'realista' enquanto Alev et al (2010) a descreveu como 'imaginativa'; 'líder' ao invés de 'melhor preparada para as atividades operacionais' como os resultados de Lemos Junior, Santini e Silveira (2015) apontaram.

Conclui-se, ainda, que a imagem da contadora, conforme os próprios profissionais de contabilidade percebem, é de uma profissional independente, sociável, sensível, íntegra, honesta, ética ao invés 
de submissa, antissocial, solitária, fria, desonesta e sem ética como notado em estudo de Moura et al (2016). Por outro lado, reafirmam-se estereótipos já relatados por outros autores, tais como inteligentes, confiantes (Davidson \& Dalby, 1993), organizadas, responsáveis e sensíveis (Tonetto, 2012), extrovertidas (Alev et al, 2010), competentes (Moura et al, 2016). Não há, portanto, consenso entre as opiniões que caracterizam a mulher contadora, mas é prevalente a estereotipagem positiva por ambos os gêneros.

Mesmo que a percepção em relação à mulher contadora tenha mudado e sua imagem seja adjetivada de forma positiva, como os resultados desta pesquisa confirmam, ainda há barreiras que as impedem de se destacarem no ambiente corporativo, como também foi confirmado em estudo internacional de Flynn, Earlie, \& Cross (2015). As percepções das contadoras sobre as desigualdades salariais e ocupacionais entre os gêneros merecem e devem ser analisados com cautela, não somente em estudos acadêmicos, mas também por entidades de classe, porque ainda apontam situações de inferioridade, subordinação e opressão, apontadas por Calás \& Smircich (2006), nas diferentes teorias de gênero.

Embora os achados desta pesquisa confirmem mudanças na estereotipagem quando é o próprio profissional a se autoestereotipar, esses resultados não podem ser generalizados à população de contadores e contadoras com registro ativo nos conselhos regionais de contabilidade brasileiros. Essa limitação decorre do fato de a investigação ser restrita à população de contadores de Uberlândia, cidade essa que embora possua representatividade no Estado de Minas Gerais (é a terceira em número de profissionais com registro ativo), pode apresentar características culturais e econômicas, principalmente, não observáveis em outras regiões geográficas. No entanto, apesar de os resultados deste estudo, ao final, se limitarem à cidade de Uberlândia, pode-se entendê-las como um indicativo de que esse estrato populacional siga tendências inerentes à população de profissionais brasileira.

Limitações quanto ao tipo de amostragem utilizada também devem ser destacadas. Optou-se pela amostragem não probabilística e intencional, critério que afasta a possibilidade de generalização dos resultados ao restante da população. A escolha da variável 'gênero feminino', se justifica em vista das desigualdades evidenciada tanto na literatura quanto nos resultados deste estudo. Entretanto, quando se trata do contexto geral envolvendo estudos de gêneros, a escolha por um único grupo de indivíduos também pode ser considerada uma limitação. Sugerem-se novos estudos envolvendo a variável gênero que se concentrem em investigar os impactos que os estereótipos presentes no cotidiano corporativo da contabilidade possam provocar na relação mulher contadora e mercado de trabalho.

\section{REFERÊNCIAS}

Abramo, L.W. (2007). A inserção da mulher no mercado de trabalho: uma força de trabalho secundária? (Tese de doutorado). Faculdade de Filosofia, Letras e Ciências Humanas, Universidade de São Paulo, São Paulo, Brasil. Recuperado de http://www.teses.usp.br/teses/disponiveis/8/8132/tde-23102007141151/pt-br.php.

Alev, K., Gonca, G., Ece, E. A., \& Yasemin, Z. K. (2010). Gender stereotyping in the accounting profession in Turkey. Journal of Modern Accounting and Auditing, 6(4), 15-25. Recuperado de https://www.researchgate.net/publication/267721005_Gender_stereotyping_in_the_accounting_profession_in_Turkey.

Alves-Mazzotti, A. J. (2008). Representações sociais: aspectos teóricos e aplicações à Educação. Múltiplas Leituras, 1(1), 18-43. Recuperado de https://www.metodista.br/revistas/revistas-ims/index.php/ML/ article/view/1169/1181. 
Anderson, J. C., Johnson, E. N., Reckers, P. M. J. (1994). Perceived effects of gender, family structure, and physical appearance on career progression in public accounting: a research note. Accounting, Organizations and Society, 19(6), 483-491. doi: https://doi.org/10.1016/0361-3682(94)90019-1

Araújo, L. C. G. (2004). As mulheres no controle do mundo: elas têm influência em todas as esferas, da política à educação. Forbes Brasil, São Paulo.

Azevedo, R. F. L. (2010). Percepção pública sobre os contadores: "bem ou mal na foto"? (Dissertação de mestrado). Faculdade de Economia, Administração e Contabilidade, Universidade de São Paulo, São Paulo, Brasil. Recuperado de http://www.teses.usp.br/teses/disponiveis/12/12136/tde-28102010165136/pt-br.php.

Boniatti, A. O., Velho, A. S., Pereira, A., Pereira, B. B., \& Pellicioli, A. (2013). Preconceitos enfrentados pelas mulheres contadoras em um escritório contábil de Caxias do Sul. In Anais do $7^{\circ}$ Seminário de Iniciação Científica de Ciências Contábeis da Faculdade da Serra Gaúcha. Caxias do Sul, RS. Recuperado de http:// ojs.fsg.br/index.php/anaiscontabeis/article/view/460-469/782.

Boniatti, A. O., Velho, A. S. de, Pereira, A., Pereira, B. B., \& Oliveira, S. M. de. (2014). A evolução da mulher no mercado contábil. Revista Gestão e Desenvolvimento em Contexto, 2(1), 19-27. Recuperado de http://177.101.254.123/index.php/GEDECON/article/view/304.

Calás, M. B., \& Smircich, L. (2006). Do ponto de vista da mulher: abordagens feministas em estudos organizacionais. In: Caldas, M., Fachin, R., \& Fischer, T. (orgs.). Handbook de estudos organizacionais. São Paulo: Atlas, v. 1.

Castro, F.V., Díaz, A.V. D., \&Vega, J. L.V. (1999). Construcción psicológica de la identidad regional: tópicos y estereotipos en el proceso de socialización, el referente a Extremadura. Badajoz: Gráfica Disputación Providencial de Badajoz.

Child, J. C. (1992). A woman's perspective of the profession. Journal of Accountancy, 173(4), 36-41. Recuperado de https://search.proquest.com/openview/92aaf0b599a68c507085cee409bf1309/1?pq-origsite $=$ gscholar\&cbl $=41065$.

Collins, K. M. (1993). Stress and departures from the public accounting profession: a study of gender differences. Accounting Horizons, 7(1), 29-38. Recuperado de https://search.proquest.com/openview/ aa67994f93e13d6ea8803b692c7a02bf/1?pq-origsite $=$ gscholar\&cbl=3330.

Conselho Regional de Contabilidade de Minas Gerais. CRCMG. (2017). Número de profissionais ativos com endereço em Minas Gerais por cidade. [Mensagem pessoal]. Mensagem recebida de <gereg@ crcmg.org.br> em 24 ago. 2017.

Cooper, C., \& Taylor, P. (2000, august). From Taylorism to Ms. Taylor: the transformation of the accounting craft. Accounting, Organizations and Society, 25(6), 555-578. doi: https://doi.org/10.1016/S03613682(99)00052-5

Cory, S. N. (1992, spring). Quality and quantity of accounting students and the stereotypical accountant: is there a relationship? Journal of Accounting Education, 10(1), 1-24. doi: https://doi.org/10.1016/ 0748-5751(92)90015-W

Davidson, R. A., \& Dalby, J. T. (1993). Personality profile of female public accountants. Accounting, Auditing \& Accountability Journal, 6(2). doi: https://doi.org/10.1108/09513579310036396 
Departamento Intersindical de Estatísticas e Estudos Socioeconômicos - DIEESE. (2014). Mulheres e homens em grupos ocupacionais homogêneos: elas tendem a ganhar menos! Pesquisa de Emprego e Desemprego. Recuperado de http://www.dieese.org.br/analiseped/2014/boletimRendimentoMulher.pdf.

Departamento Intersindical de Estatísticas e Estudos Socioeconômicos - DIEESE. (2017, março). Seade - Fundação Sistema Estadual de Análise de Dados. Mulher e trabalho, 28, 1-20. Recuperado de https:// www.dieese.org.br/analiseped/2016/2016pedmulhersao.pdf.

Estevens, M., \& Neto, M.T. (2015). Mulheres no mercado de trabalho: em Portugal a mulher contabilista. In $4^{\circ}$ Encontro Internacional Luca Pacioli de História da Contabilidade, Lisboa, Portugal. Recuperado de http://www.aeca1.org/premioefp/trabajos/2015/estevens_neto.pdf.

Flynn, A., Earlie, E. K. \& Cross, C. (2015). Gender equality in the accounting profession: one size fits all, Gender in Management: An International Journal, 30(6), p. 479-499, https://doi.org/10.1108/GM-062015-0048.

Gomes, M. (2009). Os estereótipos associados aos contabilistas e à profissão contabilística: o caso dos alunos de Ciências Económicas e Empresariais. (Dissertação de mestrado). Escola de Economia e Gestão, Universidade do Minho, Braga, Portugal.

Holcombe, L. (1973). Victorian ladies at work. Newton Abbot: David \& Charles, Holdings.

Hooks, K. L., \& Cheramy, S. J. (1994, october). Facts and myths about women CPAs. Journal of Accountancy, 178(4), 79-86. Recuperado de https://search.proquest.com/openview/9633e7ed7ef1b4d9719fa2d004b94e92/1?pq-origsite=gscholar\&cbl=41065.

Hull, R. P., \& Umansky, P. H. (1997, august). An examination of gender stereotyping as an explanation for vertical job segregation in public accounting. Accounting, Organizations \& Society, 22, p. 507-528. doi: https://doi.org/10.1016/S0361-3682(96)00028-1

International Labour Organization. ILO. (2010). Women in labour markets: measuring progress and identifying challenges. International Labour Office. Geneva: ILO. Recuperado de http://www.ilo.org/ wcmsp5/groups/public/---ed_emp/---emp_elm/---trends/documents/publication/wcms_123835.pdf.

Johnson, E. N., Reckers, P. M., \& Anderson, J. C. (1993, august). Impediments to career progression in public accounting: effects of gender, family structure, and physical appearance. Unpublished Working Paper, 19(6), 483-491. doi: https://doi.org/10.1016/0361-3682(94)90019-1

Kirkham, L. M., \& Loft, A. (1993, august). Gender and the construction of the professional accountant. Accounting, Organizations and Society, 18(6), 507-558. doi: https://doi.org/10.1016/0361-3682(93)90002-N

Kanter, R. (1977). Men and women of the corporation. New York: Basic Books.

Keiran, S. E. (2017). Gender Roles in Public Accounting and the Absence of Women in Upper Level Management. Honors Theses and Capstones. 358. Recuperado de http://scholars.unh.edu/honors/358.

Leal, E. A., Miranda, G. J., Araújo, T. S., \& Borges, L. F. M. (2014, janeiro/abril). Estereótipos na profissão contábil: a opinião de estudantes e do público externo no Triângulo Mineiro. Contabilidade, Gestão e Governança, 17(1), 134-153. Recuperado de https://cgg-amg.unb.br/index.php/contabil/article/view/623.

Lehman, C. R. (1992, april/may)."Herstory"in accounting: the first eighty years. Accounting, Organizations and Society, 17(3), 261-285. doi: https://doi.org/10.1016/0361-3682(92)90024-M 
Lemos Júnior, C. L., Santini, R. B., \& Silveira, N. S. P. (2015, jan./mar.). A feminização da área contábil: um estudo qualitativo básico. Revista de Educação e Pesquisa em Contabilidade - REPeC, 9(1), 64-83. doi: http://dx.doi.org/10.17524/repec.v9i1.1244

Leong, F. T. L., \& Hayes, T. J. (1990, december). Occupational stereotyping of Asian Americans. The Career Development Quarterly, 39(2), p. 143-154. doi: 10.1002/j.2161-0045.1990.tb00835.x

Lippmann, W. (1999). Public opinion. New York: Free Press.

Lopes, C. A. F. (2014). Estereótipo do contabilista e da profissão contabilística: o caso dos alunos do ensino secundário. (Dissertação de mestrado). Escola de Economia e Gestão, Universidade do Minho, Braga, Portugal. Recuperado de http://repositorium.sdum.uminho.pt/bitstream/1822/28010/1/C\%c3\%a1tia\%20Andreia\%20Fernandes\%20Lopes.pdf.

Louro, G. L. (1997). Gênero, sexualidade e educação: Uma perspectiva pós estruturalista (8ª ed.). Rio de Janeiro: Vozes.

Martins, R. M. L., \& Rodrigues, M. L. M. (2004). Estereótipos sobre idosos: uma representação social gerontofóbica. Millenium, 29, 249-254. Recuperado de https://repositorio.ipv.pt/bitstream/10400.19/576/1/ Estere\%C3\%B3tipos\%20sobre\%20idosos.pdf.

Miranda, G. J., Leal, E. A., Medeiros, C. R. O., \& Lemes, S. (2015, jan./abr.). Social representations of college applicants: (re)constructing the stereotype of accounting professionals. Advances in Scientific and Applied Accounting, 8(1), 20-38. doi: 10.14392/asaa.2015080102.

Miranda, V. L., \& Faria, J. A. (2016, set./dez.). Caricaturas e estereótipos do contador: como a imagem do profissional de contabilidade vem sendo veiculada em um jornal de grande circulação no Brasil? RACE-Revista de Administração, Contabilidade e Economia, 15(3), 1087-1116. doi: http://dx.doi. org/10.18593/race.v15i3.9807

Morettin, P. A., \& Bussab, W. O. (2010). Estatística básica. (6a. ed.). São Paulo, SP: Saraiva.

Moscovici, S. (1978). A representação social e psicanálise. Rio de Janeiro: Zahar.

Mota, É. R. C. F., \& Souza, M. A. (2012). A evolução da mulher na contabilidade: os desafios da profissão. In $10^{\circ}$ Congresso Virtual Brasileiro de Administração, São Paulo, SP. Recuperado de https://unibhcienciascontabeis.files.wordpress.com/2013/11/artigo_mulher_contabilista_completo.pdf.

Moura, M. F., Pereira, N. A., Miranda, G. J., \& Medeiros, C. R. de O. (2016). Herói ou vilão? Mudanças no estereótipo dos contadores na produção cinematográfica. RAGC, 4(14), 129-147. Disponível em: <http:// fucamp.edu.br/editora/index.php/ragc/article/view/769>. Acesso em: 10 abr. 2017.

Myers, D. G. (2000). Psicologia social. Rio de Janeiro: LTC.

Oliveira, T. Q., \& Leal, E. A. (2015). Estereótipo do contador: qual a percepção dos estudantes de outras áreas do conhecimento? In XVII Seminários em Administração, São Paulo, SP. Recuperado de http:// sistema.semead.com.br/18semead/resultado/trabalhosPDF/451.pdf.

Nunnally, J. C. (1970). Introduction to psychological measurement. New York: McGraw-Hill.

Passos, M. F. D. (2014). Elaboração e validação de escala de diferencial semântico para avaliação de personalidade. (Tese doutorado). Instituto de Psicologia, Universidade de Brasília, Brasília. Recuperado de http://repositorio.unb.br/bitstream/10482/1793/1/2014_MariaFabianaDamasioPassos.pdf. 
Pereira, C. A. A. (1986). O diferencial semântico: uma técnica de medida nas ciências humanas e sociais. Editora Ática.

Pinto, D. J. M. (2016). A perceção dos alunos de ciências económicas e empresariais sobre a profissão de contabilista e de auditor. (Dissertação de mestrado). Escola de Economia e Gestão. Universidade do Minho, Braga, Portugal. Recuperado de http://repositorium.sdum.uminho.pt/bitstream/1822/40882/1/ Davide\%20Jo\%c3\%a30\%20Madureira\%20Pinto.pdf.

Relação Anual de Informações Sociais (RAIS). (2017). O que é a RAIS? Recuperado de http://www.rais. gov.br/sitio/sobre.jsf.

Robbins, S. P. (2005). Comportamento organizacional. São Paulo: Pearson Prentice Hall.

Rochadel, G. M. M. (2007, abril). História do trabalho da mulher. Âmbito Jurídico, X(40). Recuperado de http://www.ambito-juridico.com.br/site/index.php?n_link=revista_artigos_leitura\&artigo_id=3898.

Sá, C. P. (1994). Sur les relations entre représentations sociales, pratiques socio-culturelles et comportement. Papers on social representations, 3(1), 1-7. Recuperado de https://core.ac.uk/download/ pdf/25772621.pdf.

Saemann, G., \& Crooker, K. J. (1999). Student perceptions of the profession and its effects on decisions to major in accounting. Journal of Accounting Education, 17(1), 1-22. doi: https://doi.org/10.1016/ S0748-5751(99)00007-X

Schlee, R. P., Curren, M. T., Harich, K., \& Kiesler, T. (07 august 2010). Perception bias among undergraduate business students by major. Journal of Education for Business, 82(3), 169-177. doi: https://doi. org/10.3200/JOEB.82.3.169-177

Scott, J. W. (1995). Gênero: uma categoria útil de análise histórica. Educação \& Realidade, 20 (2), 71-99. Disponível em https://ia700308.us.archive.org/21/items/scott_gender/scott_gender.pdf.

Shorter, E. (1976). Women's work: what difference did capitalism make? Theory and Society, 3(4), 513527. Recuperado de http://www.springerlink.com/index/U38833R04W180873.pdf.

Sidanius, J., \& Crane, M. (1989, february). Job evaluation and gender: the case of university faculty. Journal of Applied Social Psychology, 19(2), 174-197. doi: 10.1111/j.1559-1816.1989.tb00051.x

Silva, D. J. M., Silva, M. A., \& Santos, G. C. (2017). Estereótipos de gênero na contabilidade: afinal como a mulher contadora é vista? In XI Congresso AnpCont, Belo Horizonte, Minas Gerais. Recuperado de http://congressos.anpcont.org.br/xi/congresso.

Silva, J. C., Dal Magro, C. B., \& Silva, M. Z. (2016). Gender inequality in accounting profession from the perspective of the glass ceiling - Race, 15(2), 447-474. doi: http://dx.doi.org/10.18593/race.v15i2.9914.

Simões, F. I. W., \& Hashimoto, F. (2012). Mulher, mercado de trabalho e as configurações familiares do Século XX. Revista Vozes dos Vales: Publicações Acadêmicas, 1(2), 1-25. Recuperado de http://site.ufvjm. edu.br/revistamultidisciplinar/files/2011/09/Mulher-mercado-de-trabalho-e-as-configura\%C3\%A7\%C3\%B5es-familiares-do-s\%C3\%A9culo-XX_fatima.pdf.

Smith, M., \& Briggs, S. (1999). From bean-counter to action hero: changing the image of the accountant. Management Accounting, 77, 28-30. Recuperado de https://www.highbeam.com/doc/1G1-53579220. html. 
Souza Santos, M. F., \& Almeida, L. M. (2005). Diálogos com a teoria da representação social. Editora Universitária UFPE.

Splitter, K. (2013). Percepção de estudantes e professores universitários sobre a profissão do contador. (Dissertação de mestrado). Centro Sócio-Econômico, Universidade Federal de Santa Catarina, Florianópolis, Santa Catarina. Recuperado de https://repositorio.ufsc.br/xmlui/bitstream/handle/123456789/123148/323238.pdf?sequence=1\&isAllowed=y.

Splitter, K., \& Borba, J. A. (2013). O contador na sala dos espelhos: como somos vistos pelos outros e por nós mesmos? In XXXVII Encontro da Associação Nacional dos Programas de Pós-Graduação em Administração, Rio de Janeiro, RJ. Recuperado de http://www.anpad.org.br/admin/pdf/2013_EnANPAD_ EPQ2188.pdf.

Splitter, S. E., Silva, M. Z., \& Barbosa, E.T. (2017). Desigualdade salarial na profissão contábil em decorrência do gênero: um estudo à luz da violência simbólica de Bourdieu. In XIV Congresso USP de Iniciação Científica em Contabilidade, São Paulo, SP. Recuperado de http://www.congressousp.fipecafi.org/anais/ AnaisCongresso2017/ArtigosDownload/394.

Tavares, M. (2014). Estatística aplicada à administração. (3a ed.). Florianópolis: Departamento de Ciências da Administração, UFSC. Brasília: CAPES: UAB.

Tonetto, P. T. (2012). A mulher contadora: o perfil das profissionais e as perspectivas para o futuro das formadas entre 2007 a 2011 do Curso de Ciências Contábeis da Universidade do Extremo Sul Catarinense - UNESC. (Trabalho de Conclusão de Curso). Curso de Graduação em Ciências Contábeis, Universidade do Extremo Sul Catarinense, Criciúma, Santa Catarina. Recuperado de http://repositorio.unesc.net/ bitstream/1/1326/1/Patr\%c3\%adcia\%20Tramontin\%20Tonetto\%20.pdf.

Trapp, M. W., Hermanson, R. H., \& Turner, D. H. (1989). Current perceptions of issues related to women employed in public accounting. Accounting Horizons, 3(1), p. 71-94. Recuperado de https://search. proquest.com/openview/9d3c6f13eb09d344562e9c2923a69aae/1?pq-origsite=gscholar\&cbl=3330.

Wells, P. (2017). A comment on the paper 'The accountant: a character in literature' and an agenda for research on the accountant stereotype. Meditari Accountancy Research, 25(1), 28-36. doi: https://doi. org/10.1108/MEDAR-11-2016-0091

White, M. J., \&White, G. B. (2006). Implicit and explicit occupational gender stereotypes. Sex Roles, 55(34), 259-266. doi: https://doi.org/10.1007/s11199-006-9078-z

Whiting, R. H., \&Wright, C. (2001). Explaining gender inequity in the New Zealand accounting profession. The British Accounting Review, 33(2), 191-222. Recuperado de http://www.sciencedirect.com/science/ article/pii/S0890838901901611. 